\title{
A importância da educação financeira na educação de jovens e adultos
}

Antonio Paulo Guillen Hurtado ${ }^{1}$, Carlos Cesar Garcia Freitas ${ }^{2}$

\section{Resumo}

A Educação Financeira (EF) ganhou espaço e reconhecimento, aparecendo como destaque na Base Nacional Comum Curricular como forma de estimular os alunos a desenvolverem autonomia diante das práticas financeiras. $\mathrm{O}$ presente artigo tem como objetivo analisar a importância da EF na Educação de Jovens e Adultos (EJA) a partir das funções básicas dessa modalidade de ensino, suas particularidades e interesses próprios de seus alunos, bem como discutir as relações entre elas. Foi utilizada uma metodologia que abrange uma pesquisa bibliográfica, de abordagem qualitativa. Os resultados obtidos consideram que a EF é um tema relevante no âmbito educacional, em toda a Educação Básica, mais especificamente na EJA, na qual grande parte dos alunos são trabalhadores que gerenciam diariamente suas próprias finanças, portanto, a $\mathrm{EF}$ auxilia no desenvolvimento do cidadão proporcionando uma cultura de prevenção e proteção. Diante das conquistas da EJA e da EF, por meio de uma proposta pedagógica-curricular dinâmica, é possível promover uma educação que busque melhorar a qualidade do ensino considerando as experiências e trajetórias de vidas dos alunos em diversos ambientes.

\section{Palavras-chave}

Educação Financeira. Educação de Jovens e Adultos. Finanças pessoais.

\footnotetext{
1 Mestrado Profissional em Ensino pela Universidade Estadual do Norte do Paraná, Brasil; professor da Faculdade Dom Bosco, Brasil. E-mail: antoniopauloguillen.adv@ hotmail.com.

2 Doutor em Administração pela Universidade Federal do Paraná, Brasil; professor adjunto da Universidade Estadual do Norte do Paraná, Brasil. E-mail: cesarfreitas@uenp.edu.br.
} 


\title{
The importance of financial education in youth and adult education
}

Antonio Paulo Guillen Hurtado ${ }^{3}$, Carlos Cesar Garcia Freitas ${ }^{4}$

\begin{abstract}
Financial Education (FE) gained space and recognition, appearing as a highlight in the National Common Curricular Base, as a way to encourage students to develop autonomy towards financial practices. This article aims to analyze the importance of FE in Youth and Adult Education (YAE) from the basic functions of this teaching modality, its particularities and the interests of its students, and discusses its relationship with $\mathrm{FE}$ and YAE. A methodology that covers a bibliographic research, with a qualitative approach was used. The results obtained consider that $\mathrm{FE}$ is a relevant topic in the educational field, in all Basic Education, more specifically in YAE, where most of the students are workers who manage their own finances daily, therefore, FE assists in the development of the citizen providing a culture of prevention and protection. Considering the achievements of YAE and FE, through a dynamic Pedagogical-Curricular Proposal, it is possible to promote an education that seeks to improve the quality of teaching considering the experiences and life trajectories of students in different environments.
\end{abstract}

\section{Keywords}

Financial Education. Youth and Adult Education. Personal finances.

${ }^{3}$ Professional Master's in Teaching, State University of Northern Paraná, State of Paraná, Brazil; professor at Faculdade Dom Bosco, State of Paraná, Brazil. E-mail: antoniopauloguillen.adv@ hotmail.com.

${ }^{4} \mathrm{PhD}$ in Administration, Federal University of Paraná, Brazil; adjunct professor at the State University of Northern Paraná, State of Paraná, Brazil. E-mail: cesarfreitas@uenp.edu.br. 


\section{Introdução}

Apesar dos avanços obtidos pela Educação de Jovens e Adultos (EJA) no cenário educacional brasileiro, existem desafios que ainda precisam ser alcançados, como maior reconhecimento de sua importância, consolidação como política pública, investimentos em recursos educacionais, capacitação docente para atuação com o público específico e ampliação de seu conteúdo educacional. Em relação a esse último, é importante a introdução da temática Educação Financeira (EF) em seu currículo escolar (RIBEIRO et al., 2015) a partir de uma abordagem que considere as características próprias de seu público, permitindo a valorização de experiências pessoais e profissionais em relação à gestão das finanças no dia a dia.

A demanda por uma EF justifica-se pelo enfrentamento dos problemas que a sociedade vivencia, caracterizados pelo endividamento dos cidadãos diante dos apelos de consumo por meio de ofertas abundantes de produtos e serviços que "prometem" atender as mais diversas necessidades e desejos das pessoas. Diante do progresso tecnológico, do avanço das organizações, dos meios de comunicações e da globalização, povos de diferentes culturas, sem uma educação ou preparo adequado, são instigados a satisfazer seus desejos por meio dos bens de consumo (SILVA et al., 2018).

De acordo com Silva et al. (2018), isso decorre da comodidade de se comprar, aliada à oferta de crédito decorrente do considerável número de produtos que estão sendo disponibilizados no mercado e apoiados por meio de concessão de crédito do sistema financeiro. Contudo, essa oferta de produtos e facilidades pode tornar-se uma "armadilha" para algumas pessoas que não têm conhecimento crítico nesse sentido, nem dispõem de condições para uma adequada gestão financeira pessoal.

A EF é definida pela Organização para a Cooperação e o Desenvolvimento Econômico (OCDE), como o processo pelo qual as pessoas aperfeiçoam o conhecimento sobre os produtos financeiros, e, por meio de informação, formação e orientação, conseguem acessar as qualificações adequadas para avaliar riscos e oportunidades. Colabora na formação dos sujeitos, e por consequência, de toda a sociedade, sempre com uma visão de compromisso com o futuro. Procurando auxílio, é possível às pessoas realizarem escolhas corretas e tomar atitudes que propiciem bem-estar (OCDE, 2004).

No âmbito escolar, os alunos também precisam estar inseridos no contexto das finanças, sendo motivados a compreender o tema, tornando-se competentes para tomar 
decisões adequadas em relação aos assuntos financeiros, seja na sua vida particular, familiar ou comunitária (SILVA; POWELL, 2013).

A partir das orientações do Ministério da Educação e Cultura (MEC), o tema EF foi apresentado na Base Nacional Comum Curricular (BNCC/2018), como necessário ao currículo escolar, considerando que os conceitos básicos de economia e finanças devem ser estudados, de modo a potencializar a autonomia dos alunos e despertar opiniões conscientes e críticas nas diversas práticas financeiras do cotidiano.

Por sua vez, no campo educacional, temos a modalidade EJA, prevista no Art. 37, da Lei de Diretrizes e Bases da Educação (LDBEN/1996). Essa modalidade é "destinada àqueles que não tiveram acesso ou continuidade de estudos nos ensinos fundamental e médio na idade própria e constitui instrumento para a educação e a aprendizagem ao longo da vida" (BRASIL, 1996, p. 1), sendo uma importante política de inclusão social.

Dessa forma, justifica-se o presente trabalho sobre a EF no contexto da EJA, diante da necessidade de conhecimento e aprofundamento sobre o tema, haja vista que muitos de seus estudantes, apesar de já possuírem algum tipo de conhecimento sobre o tema, enfrentam desafios e problemas de ordem financeira que limitam suas oportunidades de mudança de vida.

O objetivo desta pesquisa é analisar a importância da EF na EJA, a partir das suas funções básicas e características próprias de seus alunos, pois se trata de um público que vive os desafios de administrar suas demandas financeiras, devido aos gastos com moradia, alimentação, saúde, educação e aposentadoria. Ainda, ao apropriar-se dos conhecimentos desse campo, poderão aperfeiçoá-los às suas próprias experiências, o que possibilitará enfrentar os problemas com mais eficiência e eficácia, além de acompanhar melhor as mudanças sociais. Quanto à metodologia, foi realizada uma pesquisa bibliográfica de abordagem qualitativa, a partir de referências teóricas que tratam do assunto.

\section{Educação de jovens e adultos}

O debate em torno da EJA na atualidade aborda questões para discussão sobre acesso, permanência dos alunos na escola e aceleração do aprendizado. Leva a uma reflexão que permita a garantia do direito à educação de qualidade para constituir "cidadãos críticos e participativos" (FERREIRA; RODRIGUES, 2016, p. 573). 
Uma educação de qualidade deve permitir que os sujeitos adquiram liberdade sobre suas decisões, tenham pensamento crítico e participem ativamente na sociedade. $\mathrm{O}$ direito à educação de qualidade está previsto de no Art. 205, da Constituição Federal de 1988, ao dispor: “A educação, direito de todos e dever do Estado e da família, será promovida e incentivada com a colaboração da sociedade, visando ao pleno desenvolvimento da pessoa, seu preparo para o exercício da cidadania e sua qualificação para o trabalho" (BRASIL, 1988, p. 1).

A EJA organiza-se como uma modalidade de ensino com muitas particularidades, pois abrange pessoas das mais variadas idades, podendo se encontrar em uma única sala de aula, adolescentes com 15 anos, adultos com 30 anos e idosos com 70 anos ou mais. Esses grupos possuem experiências distintas de vida e a maioria se situa no mundo do trabalho, diferentemente do aluno em processo regular de ensino que está estudando para ter uma vivência futura, e consequentemente, realizar sonhos e projetos no decorrer de sua história de vida. Assim, os alunos que participam da EJA carregam seus anseios e suas experiências vivenciadas (BEZERRA; SANTANA, 2011), depositando as esperanças de uma aplicação mais imediata do estudo, no sentido de modificar sua atual situação.

O papel da EJA é contribuir com uma educação de qualidade na formação dos indivíduos, de forma que se tornem sujeitos ativos na sociedade em que vivem. Apesar de estarmos distantes de uma situação ideal, a EJA atualmente é considerada uma política pública que busca a formação dos jovens e adultos, proporcionando novas oportunidades na vida pessoal ou profissional do aluno (SANTOS; SOARES; TORRES, 2017).

$\mathrm{Na}$ atualidade, com o reconhecimento de políticas públicas, leis e diretrizes pedagógicas estabelecidas pela LDBEN/1996, a EJA é ofertada como uma modalidade de ensino e está inserida nas escolas "de forma sistemática, obrigatória e gratuita pelo Estado" (BEZERRA; SANTANA, 2011, p. 99).

A referida lei organiza o sistema educacional do Brasil em dois níveis de ensino: Educação Básica e Ensino Superior. A Educação Básica é formada pela Educação Infantil, Ensino Fundamental e Ensino Médio, e o Ensino Superior aborda cursos de tecnologia, bacharelado e licenciatura (BRASIL, 1996). Por sua vez, a Educação Básica pode ser oferecida nas seguintes modalidades: Educação de Jovens e Adultos (EJA), Educação Profissional, Educação Especial, Educação Indígena e Educação a Distância. Em relação à EJA, dispõe o Art. 37: 
Art. 37. A educação de jovens e adultos será destinada àqueles que não tiveram acesso ou continuidade de estudos no ensino fundamental e médio na idade própria.

$\S 1^{\circ}$ Os sistemas de ensino assegurarão gratuitamente aos jovens e aos adultos, que não puderam efetuar os estudos na idade regular, oportunidades educacionais apropriadas, consideradas as características do alunado, seus interesses, condições de vida e de trabalho, mediante cursos e exames. (BRASIL, 1996).

Portanto, os alunos que participam dessa modalidade são pessoas que provavelmente não tiveram oportunidades de ingressar ou não conseguiram concluir a vida escolar por diversos motivos, seja pela distância da escola, falta de oportunidade, necessidade de trabalhar, dentre outros (ARROYO, 2005).

Tendo em vista que atualmente são inúmeros os jovens e adultos que não conseguiram concluir o ensino básico na idade regular, a EJA torna-se mais que um direito, pois é uma forma de se efetivar o pleno exercício da cidadania como condição para que o indivíduo consiga obter plena participação na sociedade. Por meio dela, torna-se possível o desenvolvimento da democracia, justiça, igualdade, desenvolvimento socioeconômico e científico, permitindo a construção de uma cultura de paz (BRASIL, 2008).

Ressalta-se que nessa modalidade de ensino, o público não são crianças em idade regular, mas jovens, adultos e idosos que possuem suas experiências de vida pessoal e profissional, que devem ser consideradas no âmbito das práticas pedagógicas. Cada aluno apresenta seus interesses, motivações e atitudes pessoais, que podem variar de um para outro, pois o jovem tem uma perspectiva de futuro, ou seja, aquilo que será possível conquistar no decorrer da sua vida pessoal e profissional; o adulto normalmente está preocupado com sua vida profissional, buscando oportunidades no mercado de trabalho; enquanto o idoso deseja efetivar sua cidadania, alcançando respeito para que possa viver com dignidade dentro da sociedade (PARANÁ, 2006).

Nessa perspectiva, o Parecer CNE/CEB no 11/2000 com fundamento na Lei 9.394/96, apresenta três funções básicas do ensino de caráter regular à EJA: função reparadora, função equalizadora e função permanente. A função reparadora permite a entrada dos cidadãos no âmbito dos direitos civis que lhes foram restringidos, com uma escola de qualidade em reconhecimento a uma igualdade intrínseca em todo ser humano. A função equalizadora possibilita a reentrada no sistema educacional daqueles que tiveram que interromper seus estudos por diversos motivos, e ainda que tardia, essa inserção contribui para abertura de novas expectativas, seja no mundo de trabalho, assim como na vida social. A função permanente, também chamada de qualificadora é o principal sentido da EJA, ou seja, 
desenvolver e adequar o aluno como ser humano, criando uma sociedade solidária e igualitária, respeitando as diversidades (BRASIL, 2000).

Por meio dessas funções, a EJA enquanto modalidade de ensino busca proporcionar que o sujeito tenha condições de desenvolver sua autonomia, reflexão crítica e participação ativa nas decisões políticas que envolvem sua vida. Todavia, é preciso considerar as particularidades de cada aluno, suas expectativas, condições de vida e trabalho, também seus objetivos de vida (FERREIRA; RODRIGUES, 2016).

Desse modo, a EJA abrange um conjunto vasto e diversificado de jovens e adultos provindos das mais variadas partes da classe trabalhadora. Assim, existe diversidade de situações dentro desse contexto escolar, que envolvem questões étnico-raciais, de gênero, culturais, de orientações sexuais, de privação de liberdade, mentais, físicas, psíquicas, diante de aspectos culturais e econômicos que devem ser consideradas no processo de ensino e aprendizagem (BRASIL, 2008).

Apesar de não ser regra, geralmente o público da EJA são jovens, adultos e idosos de uma classe economicamente baixa, que lutam para sobreviver, apresentando certa desconfiança em relação ao ensino. Muitos estão à margem da sociedade e são vistos como analfabetos ou incapazes de aprender, em sua maioria são indivíduos adultos sem qualificação profissional, que se distanciaram do sistema educacional, ficando longe de qualquer pretensão universitária (OLIVEIRA, 1999), buscando no estudo resgatar sua dignidade como cidadão.

Até o final do século 20, a EJA ocupou um espaço muito reduzido dentro do sistema educativo brasileiro, sendo marcada por apresentar um aspecto compensatório e desprovido de valor social (ARROYO, 2005). Em muitas circunstâncias, os conteúdos, métodos e materiais didáticos eram considerados inadequados, reproduzindo uma forma pobre que remetia ao sistema de ensino tradicional (GADOTTI; ROMÃO, 2006). Atualmente, para aperfeiçoar e orientar essa modalidade de ensino, o MEC tem aplicado recursos buscando aproximar o processo inicial de alfabetização e a continuação dos estudos nas turmas da EJA. Dessa forma, com a Resolução CD/FNDE n 48/2012, transferem-se aos estados, municípios e Distrito Federal, recursos financeiros para preservação de novas turmas (BRASIL, 2012).

Conforme dados apresentados pelo Instituto Nacional de Estudos e Pesquisas Educacionais Anísio Teixeira (INEP), no Censo Escolar, realizado em 2018, foram registrados na esfera estadual e municipal 1.822.818 (um milhão, oitocentos e vinte e dois mil, oitocentos e dezoito) alunos no Ensino Fundamental, e, 1.055.347 (um milhão, cinquenta e cinco mil, trezentos e quarenta e sete) alunos no Ensino Médio, totalizando 2.878.165 (dois milhões, oitocentos e setenta e oito mil, cento e sessenta e cinco) alunos matriculados na EJA 
(BRASIL, 2018), o que representa um número significativo no âmbito educacional.

Destarte, a educação deve formar alunos que aprendam continuamente, refletindo de maneira crítica, agindo com responsabilidade, participando ativamente do trabalho de forma solidária, seguindo as mudanças que ocorrem na sociedade, colaborando na solução dos problemas de modo ágil e eficaz, utilizando conhecimentos "científicos, tecnológicos e sóciohistóricos" (KUENZER, 2000, p. 20).

Por meio dessa modalidade de ensino, é desejável que o aluno se torne capaz de construir e de se apropriar do conhecimento, aplicando-o no mundo do trabalho no qual exercerá sua cidadania, criando novos significados em suas experiências socioculturais (PARANÁ, 2006). Dessa forma, considerando os desafios enfrentados pela EJA, apresenta-se a EF como um tema relevante que pode auxiliar no processo de formação desses alunos.

\section{Educação Financeira}

A EF é um tema de relevância no contexto financeiro atual. O número crescente de produtos que estão sendo disponibilizados no mercado financeiro exige cada vez mais conhecimentos, que poderão ser adquiridos por meio da EF (SILVA; JÚNIOR, 2006). Dessa forma, o cidadão precisa constantemente se atualizar, considerando o desenvolvimento sem precedentes ocorrido na indústria, no comércio e na prestação de serviços, principalmente no que se refere à tecnologia (CAMPOS; SILVA, 2014).

A proposta da EF é formar o indivíduo no que tange ao planejamento e a forma de como administrar os recursos monetários, auxiliando-o na tomada de decisões coerentes que permitam-lhe poupar e investir, garantindo assim, viver mais tranquilo financeiramente, seja no presente ou no futuro (MORAES, 2019).

Diante das céleres e constantes mudanças sociais e econômicas ocorridas nos últimos anos, acaba sendo frequente o aumento da obscuridade sobre os produtos financeiros que são apresentados à população, que adquire tais produtos sem ter consciência das consequências que isso pode causar, sendo indiscutível a necessidade de um debate sobre questões pertinentes (CAMPOS; SILVA, 2014).

Segundo os dados apresentados pela Pesquisa Nacional de Endividamento e Inadimplência do Consumidor (PEIC, 2019), em relação ao número total de famílias do Brasil, no período de janeiro de 2016, havia um total de 61,6\% de endividados; no período de janeiro de 2017, o total era de 58,7\% de endividados; em janeiro de 2018, o total estava em $61,3 \%$; e em abril de 2019, o total de endividados era de 62,7\%; sendo possível perceber que 
a EF ainda não faz parte do dia a dia da população, devido à falta de planejamento do orçamento e do consumo consciente (MORAES, 2019).

Todavia, se houvesse EF na Escola Básica seria mais efetiva a consciência e o planejamento entre a população, e possivelmente esses números seriam reduzidos, pois um dos seus principais objetivos é educar para o consumo (ENEF, 2011).

No âmbito internacional, as atuais crises financeiras trazem consequências para toda a sociedade. Destarte, os prejuízos dessa situação têm provocado reformas dos sistemas financeiros em praticamente todos os países, robustecendo estratégias de aprimoramento, incentivando a introdução de matérias sobre finanças no currículo escolar (HOFMANN, 2013).

A OCDE (2004) apresenta a EF como o processo no qual o indivíduo, e consequentemente, a sociedade, aperfeiçoa sua compreensão em relação aos produtos financeiros, e por meio de informação, formação e orientação, seja capaz de analisar riscos e oportunidades, favorecendo o seu bem-estar, contribuindo para um futuro de mais oportunidades.

Não é de hoje que a EF tem seu reconhecimento, pois na Idade Média, apesar de o termo não ser empregado, já existia a preocupação com as possíveis maneiras de poupar e também com a falta de dinheiro (D’AQUINO, 2007). Atualmente, em um cenário diverso, é nítido que as novas gerações não estão sendo formadas para exercer um papel adequado diante da economia (LUCCI et al., 2006). Sendo assim, a escola, famílias e sociedade devem exercer a responsabilidade de formar crianças e adolescentes para a vida financeira, de maneira saudável, atuando de forma crítica e consciente, onde todos consigam realizar corretamente seu papel na sociedade organizada (REBELLO; ROCHA FILHO, 2015).

Algumas ações podem ser praticadas para potencializar um programa de EF, seguindo orientações da OCDE, quais sejam o incentivo da cultura de poupança; construção de conceitos de crédito, investimentos e consumo consciente; acompanhamento da qualidade dos programas de EF. É essencial que as instituições de ensino colaborem para que a educação também seja direcionada às questões financeiras, permitindo o desenvolvimento dos indivíduos de forma que consigam administrar seus recursos financeiros adequadamente (SAVOIA; SAITO; SANTANA, 2007).

Nesse sentido, tem crescido o número de iniciativas, privadas e públicas, que almejam articular o tema EF com a sociedade. Algumas ideias são no sentido de que a temática deve ser inserida também nas escolas para a formação dos alunos (DA SILVA; SELVA, 2018).

No Brasil, no ano de 2010, com Decreto Federal n 7.397/2010, foi criada a Estratégia 
Nacional de EF (ENEF), com o propósito de propagar e efetivar a EF no país.

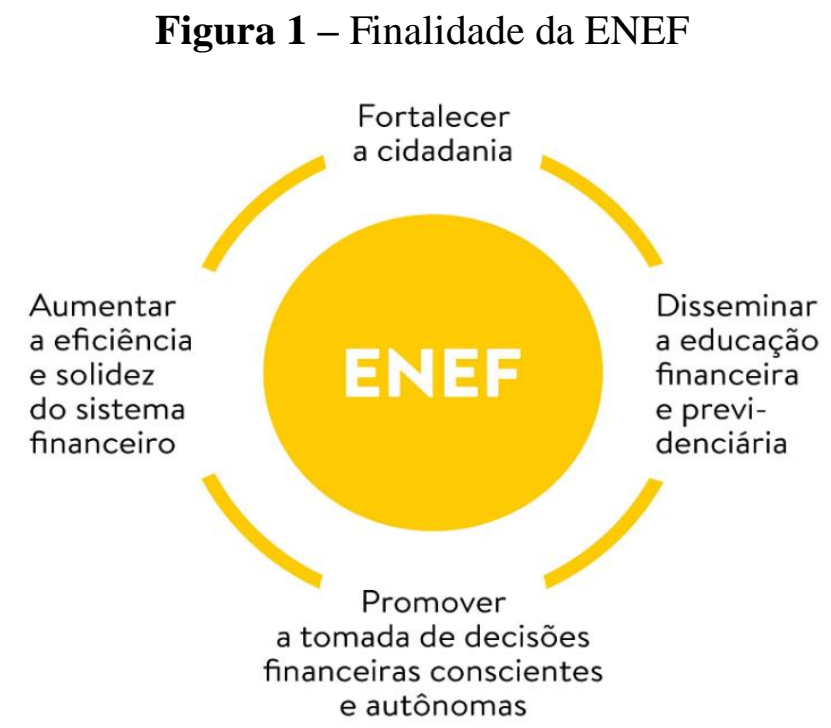

Fonte: ENEF (2018)

A finalidade da ENEF é colaborar para a consolidação da cidadania auxiliando a população na tomada de decisões financeiras adequadas e prudentes. Oito órgãos e entidades governamentais e quatro organizações da sociedade civil ${ }^{5}$ compõem o Comitê Nacional de EF (CONEF).

No ano de 2011, foi criada a Associação de EF do Brasil (AEF - Brasil) por meio das quatro organizações da sociedade civil que constituem a CONEF. Trata-se de uma organização que não tem finalidade lucrativa, com o intuito de estimular a EF no Brasil e contribuir na realização de ações transversais.

$\mathrm{O}$ fato do Brasil não possuir ainda uma cultura fundamentada na EF tem penalizado a população, em especial a parcela mais pobre, que não tem reservas para fazer frente aos revezes da vida. A crise econômica tem atingido todas as classes sociais, especialmente aqueles que têm uma renda baixa. Assim, o fato de sermos um país consumista, juntamente ao cenário econômico atual, tem gerado situações cada vez mais desastrosas, que impactam além do âmbito financeiro (SILVA et al., 2018).

De acordo com Bader e Savóia (2013, p. 212), “pessoas e famílias que vivem em situação de miséria acabam apresentando algumas necessidades urgentes - tais como

\footnotetext{
${ }^{5}$ São oito órgãos e entidades governamentais que fazem parte, sendo eles: Banco Central do Brasil; Comissão de Valores Mobiliários; Superintendência Nacional de Previdência Complementar; Superintendência de Seguros Privados; Ministério da Justiça; Ministério da Previdência Social; Ministério da Educação, e Ministério da Fazenda. Também fazem parte, quatro organizações da sociedade civil são elas: ANBIMA; BMF \& Bovespa; CNseg e FEBRABAN (ENEF, 2011).
} 
alimentação, saneamento básico, habitação, mínimo de infraestrutura - que as suas necessidades de inclusão financeira ficam em segundo plano". Contudo, por meio da educação é possível mudar essa situação, o que se aplica também à EF, permitindo assim, que o indivíduo conquiste seu espaço na sociedade e tenha condições de adquirir conhecimento e lutar pelos seus direitos, de forma que consiga exercer uma vida com dignidade.

No entanto, é preciso trabalhar a EF de modo amplo, pois, via de regra, tem sido relacionada somente aos conteúdos de Matemática Financeira, como exemplo: juros simples e compostos, descontos, porcentagens, amortizações. Mas esses são assuntos correspondentes apenas a uma parcela da disciplina, que envolve tantos outros, como consumo planejado e consciente; orçamento; planejamento financeiro; utilização do crédito e gerenciamento de dívidas; juros; poupança; administração das dívidas; empreendedorismo, aplicações e investimentos; responsabilidade socioambiental; plano de previdência (CAMPOS, 2012). Conforme preconiza a ENEF (2011b, p. 59), a EF "além de informar, forma e orienta indivíduos que consomem, poupam e investem de forma responsável e consciente, propiciando base mais segura para desenvolvimento do país".

Sendo assim, a EF vai além de um conhecimento especializado e pontual, visto que auxilia no desenvolvimento questionador do cidadão, permitindo que ele consiga traçar objetivos na vida, assim como eleger os recursos corretos para conquistá-los. A EF proporciona uma cultura de prevenção e proteção, além de ensinar o indivíduo a planejar a curto, médio e longo prazo, auxiliando-o em uma melhoria da sua própria situação, e consequentemente, de sua família.

Devido às grandes transformações ocorridas na sociedade atual, em razão das novas tecnologias, existe uma maior oportunidade para o empreendedorismo individual nas mais diversas classes sociais, e a EF é extremamente importante para o entendimento do sistema monetário nacional e mundial. Assim, a Base Nacional Comum Curricular (BNCC) orienta que assuntos relacionados à EF sejam discutidos na escola favorecendo "um estudo interdisciplinar envolvendo as dimensões culturais, sociais, políticas e psicológicas, além da econômica, sobre as questões do consumo, trabalho e dinheiro" (BNCC, 2018, p. 269).

Abordados de forma transversal, os conteúdos devem ser trabalhados de forma contextualizada aos temas contemporâneos. Dentre temas variados, a EF apresenta sua importância conforme mencionado na BNCC, pois "promove um diálogo articulador entre as áreas do conhecimento porque entende que são necessárias contribuições de várias delas para que vicejem conceitos e comportamentos financeiros saudáveis" (CONEF, 2014, p. 14). 


\section{Metodologia}

Esse artigo buscou analisar a importância da EF na EJA, apresentando as funções básicas dessa modalidade de ensino, suas particularidades e interesses próprios de seus alunos. Discutiu-se sua relação com a EF, destacando-se ações desenvolvidas com o propósito de propagar e estimular as pessoas a obterem conhecimentos financeiros que possam ajudá-las a superar suas dificuldades financeiras.

Para isso, foi realizada uma pesquisa bibliográfica de abordagem qualitativa, a partir do levantamento de referências teóricas que abordam assuntos e problemas já analisados e divulgados por meios eletrônicos ou escritos (FONSECA, 2002). Justifica-se a metodologia pela natureza do estudo e pelas fontes de dados utilizadas, essas de referências teóricas, como livros, artigos científicos e dissertações, diante da necessidade de legitimação acadêmica das informações (LAKATOS; MARCONI, 2003) e da sua consequente reflexão teórica. A pesquisa de abordagem qualitativa busca compreender determinado grupo social e os fenômenos que o envolvem, não necessitando apresentar números diante das questões abordadas, mas procurando entender o contexto real diante das relações sociais, sendo possível descrevê-las e explicá-las (RICHARDSON, 1999).

Portanto, os encaminhamentos metodológicos de pesquisa bibliográfica de abordagem qualitativa possibilitaram a análise dos conteúdos publicados, tanto de forma escrita ou eletrônica, permitindo uma reflexão e discussão sobre o assunto, de modo que novos estudos poderão ser realizados, haja vista a importância e o vasto campo de pesquisa.

\section{Resultados e Discussão}

A partir da pesquisa realizada, percebe-se que se capacitar com o intuito de gerenciar as finanças pessoais é um desafio para o qual muitas pessoas não alcançam êxito. Todavia, é necessário que os indivíduos adquiram conhecimentos e instrumentos que permitam compreender a dinâmica financeira em seu contexto social. Nisso reside a relevância da EF, sendo oportuno que, quanto mais cedo aprende-se sobre ela, maior será a chance de superar as dificuldades relacionadas à gestão do dinheiro (COELHO, 2014).

$\mathrm{O}$ conceito de finanças pessoais pode ser definido como "a ciência que estuda a aplicação de conceitos financeiros nas decisões financeiras de uma pessoa ou família. Em finanças pessoais são considerados os eventos financeiros de cada indivíduo, bem como sua fase de vida para auxiliar no planejamento financeiro" (CHEROBIM; ESPEJO, 2010, p. 1). 
As finanças pessoais estão relacionadas aos resultados que o indivíduo obtém no âmbito econômico, sejam eles positivos ou negativos; a maneira como cada um procede sob o enfoque financeiro irá refletir diretamente em sua vida (CONTO et al., 2015), de sua família e na sociedade em que vive.

O presente estudo demonstra ainda que a questão financeira perpassa todas as dimensões da vida de um indivíduo, como alimentação, habitação, saúde, educação, lazer, família, entre outras e seu impacto não se limita a sua esfera individual. Suas ações financeiras têm reflexo, em maior ou menor grau, em seu bairro, sua cidade, seu estado, seu país, em diante e impactarão não somente na esfera econômica, como também social e ambiental. Na percepção dessa profunda e complexa relação, está a preocupação em disseminar a EF para todos os públicos.

Conforme apresentado, a EJA apresenta três funções legais: função reparadora, função equalizadora e função permanente. A função reparadora tem o intuito de possibilitar e restaurar o acesso a direitos negados, e que esses direitos sejam garantidos com qualidade e reconhecimento de igualdade entre todos os seres humanos. Assim, considera-se a alfabetização como um direito humano fundamental. A função equalizadora abrange os diversos trabalhadores, bem como aposentados, donas de casa, encarcerados, entre outros, via de regra, os mais pobres, para que consigam reentrar no sistema escolar, haja vista, que tiveram uma interrupção em determinado momento de suas vidas. Essa função tem o objetivo de inseri-los no mercado de trabalho e na vida social de forma participativa criando novas oportunidades. Por fim, a função permanente, também conhecida como qualificadora, é o sentido de existência da EJA, considerando o potencial de desenvolvimento e de adequação que cada um possui. Busca educar o aluno de forma universal, preservando princípios de solidariedade e igualdade, respeitando sempre a diversidade.

O diálogo entre a EF e EJA é uma oportunidade de oferecer aos alunos, conhecimentos e instrumentos para que eles possam decidir de maneira consciente como administrar seus recursos, aumentando as chances de se evitarem problemas relacionados ao dinheiro, seja no momento presente, assim como no futuro. A EF pode proporcionar ao aluno da EJA uma visão mais crítica sobre sua realidade, em especial aos contornos financeiros que moldam a sociedade, em especial aos produtos de consumo e publicidades.

Essa relação existente entre a EF e a EJA permite a efetivação das funções legais previstas nessa modalidade de ensino, pois os conhecimentos financeiros contribuirão para que o aluno administre e planeje seus recursos e, consequentemente, se desenvolverá um direito fundamental, no que se refere à educação, além de que muitos alcançarão novas 
oportunidades no mercado de trabalho e na vida em sociedade, ampliando sua participação e o desenvolvimento de seu potencial.

Como já destacado, os perfis dos alunos da EJA são diversos, compreendidos por jovens, adultos e idosos, em sua maioria, oriundos de uma classe economicamente baixa. Pessoas que buscam resgatar o tempo perdido de estudo, na esperança de mudar sua realidade, e a EF pode auxiliá-los nesse processo, pois os conhecimentos que carregam em si são de aplicação direta aos alunos e podem favorecer a uma transformação mais imediata de suas vidas. Quando trabalhada na educação básica, muitos dos conhecimentos terão aplicação no futuro, diferentemente da EJA.

Os alunos da EJA possuem experiências de vida pessoal e profissional que precisam ser consideradas no campo das práticas pedagógicas (BEZERRA; SANTANA, 2011), o que não é diferente para a EF, que deve privilegiar essas realidades, de modo a tornar o processo de ensino aprendizagem significativo para o aluno. A desconfiança em relação ao ensino é uma característica de muitos alunos da EJA (OLIVEIRA, 1999) reforçada pela falta de significado do que se está aprendendo. O que é trabalhado com os alunos, muitas vezes, é estranho ao seu contexto, nisso reside a importância da vivência do estudante ser um ponto de partida para a busca do conhecimento. Estudar EF deve ser uma ação que parte da reflexão pessoal de sua própria condição financeira.

Ainda, o conhecimento adquirido por meio da EF poderá ser utilizado de maneira reflexiva, como propõe o Decágono de Competências do CONEF (2014), possibilitando aos alunos debaterem os seus direitos e deveres, participarem de decisões financeiras responsáveis, realizarem a distinção do que seria um desejo ou uma necessidade de consumo, interpretarem textos do mundo financeiro, atuarem como multiplicadores, elaborarem planejamentos financeiros, tendo em vista uma preocupação com o futuro.

Portanto, a EF deve levar o aluno a refletir sobre sua realidade não apenas no sentido micro, como também no macro, refletindo o processo de marginalização que a atual sociedade capitalista tem gerado pelo consumo. Por seus conteúdos, é possível compreender a dinâmica do dinheiro, seus benefícios e malefícios, o que permite repensar que tipo de sociedade desejamos, individualista ou coletiva. É preciso que a EF seja trabalhada em uma perspectiva que possa quebrar o ciclo de marginalização no qual estão envolvidos os alunos da EJA, buscando contemplar valores críticos e o desejo de alcançar um novo tipo de desenvolvimento mais humano e ambientalmente sustentável.

Nesse sentido, tem-se ainda a possibilidade de desenvolver práticas pedagógicas na perspectiva da Economia Solidária (ES), sendo uma alternativa abrangente que vai além de 
uma EF em favor do empreendedorismo individual. Cabe destacar que a ES é uma forma distinta de produção, compra, venda e troca de tudo aquilo que é necessário para viver. Diferentemente da economia convencional, na qual se estabelecem patrões e empregados, na ES é possível que os trabalhadores sejam donos de seus próprios negócios, tomando decisões, dividindo o trabalho e compartilhando resultados. (BRASIL, 2015).

Dessa forma, diante da lógica de uma economia liberal e globalizada, aparece a ES como uma forma alternativa de organizar a produção, procurando implantar outro modelo de sociedade, sendo um setor econômico planejado com dinamismo, eficiente na geração de trabalho e renda, capacitado em promover a inclusão social (ZUCCHETTI; MOURA; MENEZES, 2011). Trabalhando-se a EF, com base nos valores da ES, podem-se apresentar aos alunos da EJA novas perspectivas em relação aos processos econômicos, valorizando o desenvolvimento social e humano com a formação integral do aluno, para além da reprodução do capital.

O que se defende aqui é o uso da EF para promoção de novos valores econômicosociais que possam romper o atual modelo hegemônico de trabalho, pelo qual se caracterizam duas figuras, o proprietário dos meios de produção e os trabalhadores que trabalham para os proprietários. Por meio do conhecimento da dinâmica do capital, trabalhada na EF, é possível empoderar os trabalhadores para que possam buscar seus próprios meios de trabalho e evitar a dependência de um emprego tradicional. A conjunção entre EF e empreendedorismo, como foco na ES pode tornar-se um caminho viável para um novo projeto de desenvolvimento mais humano, que leve em consideração os fatores econômicos e sociais. Para tanto, é preciso privilegiar uma cultura empreendedora, fundamentada na diversidade de modelos de empreendedorismo. De acordo com Dreher (2004), existem muitas iniciativas ou formas de empreendedorismo, podendo ser o de perfil empreendedor, gestão empreendedora, intraempreendedorismo, ou, empreendedorismo coletivo. Essa cultura busca dar ênfase a novas oportunidades, e proporcionar meios para criação de uma estrutura adequada ao planejamento e estratégias de oportunidades de negócios, em especial autogeridos.

Com novas propostas pedagógicas centradas no aluno como sujeito ativo no processo de ensino e aprendizagem, evidencia-se que a EF promovida na EJA poderá despertar e estimular uma cultura empreendedora, na qual o aluno seja capaz de criar suas próprias oportunidades de trabalho e geração de renda, superando obstáculos financeiros, assim como demais desafios que normalmente ocorrem durante a vida. 
Tendo em vista que na EJA devem ser abordadas ações pedagógicas que considerem o perfil do aluno, com necessidades de escolarização formal, mas também no que diz respeito às exigências do mercado de trabalho (PARANÁ, 2006, p. 30), por meio da EF, é possível estimular o desenvolvimento de competências individuais e sociais de cada aluno, possibilitando "a compreensão dos impactos das inovações tecnológicas nas relações de produção, trabalho e consumo", por meio do planejamento e consumo consciente (BRASIL, 2018, p. 568).

Diante das transformações ocorridas na sociedade em função das novas tecnologias, os trabalhadores participam cada vez mais em diversos setores da produção. Como grande parte dos alunos da EJA são trabalhadores inseridos no mercado de trabalho, por intermédio da EF nas escolas é possível desenvolver a criatividade, sensibilidade e autocrítica em relação às decisões financeiras, diminuindo as desigualdades sociais, abrindo mais espaço para o empreendedorismo em todas as classes sociais (BRASIL, 2018).

Apesar de todas as conquistas alcançadas na EJA, é necessária a construção e implementação de uma proposta pedagógico-curricular dinâmica, com proposta de educação de qualidade, conforme previsto em lei, que permita aos alunos o aprendizado de conteúdos curriculares que sejam relevantes em suas experiências e trajetórias de vida, no âmbito pessoal, familiar ou profissional (PARANÁ, 2006). Ainda que a EJA não tenha seu espaço reconhecido junto a BNCC, pois o documento não abrange no seu texto os sujeitos da aprendizagem dessa modalidade educacional, como trabalhadores do campo, ribeirinhos, indígenas, quilombolas, entre outros, que constituem um público diversificado pertencente ao ambiente da EJA. Destarte, por meio de debates educacionais seria possível a elaboração de currículos adequados para a EJA, dentre os quais estejam previstos como objetivos da aprendizagem a EF para contribuir de forma significativa na vida do aluno.

\section{Considerações finais}

Diante do contexto histórico da EJA, no qual houve algumas omissões e pouco interesse durante alguns períodos por parte dos órgãos públicos, a EJA se apresentou como uma modalidade de ensino com características particulares, sendo de grande importância no cenário nacional no setor educacional, e, consequentemente, na conquista pela democracia. 
Considerando que a educação é um direito de todos, conforme previsto na Carta Magna, o Estado e as famílias são responsáveis por promover e motivar a participação dos indivíduos da sociedade no âmbito educacional, pois, assim, será possível o exercício pleno da cidadania, em que o aluno terá oportunidade de construir seu conhecimento e aplicá-lo nos diversos ambientes de trabalho.

Por sua vez, dentro desse espaço educacional, alguns temas relevantes do cotidiano dos alunos não são abordados de forma adequada. No que se refere à $E F$, ainda são necessárias algumas ações para que os alunos da educação básica tenham contato com o assunto. Tendo em vista o aumento constante de produtos financeiros disponíveis no mercado e as constantes mudanças socioeconômicas, a EF contribui na formação do indivíduo, auxiliando-o no planejamento, na maneira de como gerenciar seus recursos financeiros e na sua tomada de decisões, de forma que as decisões presentes beneficiem o seu próprio futuro, e, em consequência, o futuro de toda a sociedade.

Diante das funções legais da EJA, a EF contribui no exercício desse direito fundamental, que é a própria educação, promovendo novas oportunidades dentro da sociedade, auxiliando o aluno no desenvolvimento de seu potencial, fortalecendo sua participação e autonomia frente aos diversos desafios financeiros existentes na vida social.

Apesar de caminhar ainda em passos lentos nas escolas brasileiras, a EF vai ganhando espaço e aos poucos, conquistando seus objetivos, previstos no Plano Diretor da ENEF. Tanto que, na atual BNCC, o tema aparece de forma relevante como parte do currículo escolar, estimulando os alunos a potencializarem sua autonomia no que tange ao desenvolvimento de práticas financeiras. Em relação à EJA, o texto da $\mathrm{BNCC}$ não valorizou as particularidades se seus alunos, sendo necessária uma reconstrução curricular que respeite as diversidades, bem como contribua para a autonomia e emancipação dos indivíduos.

Tendo em vista que na modalidade EJA devem ser trabalhados conteúdos e ações pedagógicas que valorizem o perfil dos alunos, por meio da EF será possível despertar interesse por novos conhecimentos, desenvolvimento de criatividade e autocrítica, de forma a contribuir com os indivíduos na administração e gerenciamento de suas finanças no momento atual, de maneira que essas decisões financeiras possam favorecê-los no futuro.

\section{Referências}

ARROYO, M. G. Educação de jovens-adultos: um campo de direitos e de responsabilidade pública. In: SOARES, L.; GIOVANETTI, M. A. G. C.; GOMES, N. L. (org.). Diálogos na educação de jovens e adultos. Belo Horizonte: Autêntica, 2005. p. 19-50. 
BADER, M.; SAVOIA, J. R. F. Logística da distribuição bancária: tendências, oportunidades e fatores para inclusão financeira. Revista de Administração de Empresas, São Paulo, v. 53, n. 2, mar./abr. 2013. Doi: 10.1590/S0034-75902013000200008.

BEZERRA, G. F.; SANTANA, M. S. R. Educação de jovens e adultos: modalidade de ensino e direito educacional. Interfaces da Educação, Paranaíba, v. 2, n. 5, p. 93-103, 2011. Doi: 10.26514/inter.v2i5.592.

BRASIL. [Constituição (1988)]. Constituição da República Federativa do Brasil. Brasília, DF: Senado Federal, 1988.

BRASIL. Decreto n ${ }^{\circ}$ 7.397, de 22 de dezembro de 2010. Institui a Estratégia Nacional de Educação Financeira - ENEF, dispõe sobre a sua gestão e dá outras providências. Diário Oficial da União, Brasília, DF, 23 dez. 2010. Disponível em:

http://www.planalto.gov.br/ccivil_03/_Ato2007-2010/2010/Decreto/D7397.htm. Acesso em: 25 set. 2019.

BRASIL. Ministério da Economia. Secretaria de Trabalho. Economia Solidária. 2015. Disponível em: http://trabalho.gov.br/trabalhador-economia-solidaria. Acesso em: 30 abr. 2020.

BRASIL. Ministério da Educação. Conselho Nacional de Educação. Câmara de Educação Básica. Parecer CNE/CEB no 11/2000. Disponível em:

http://portal.mec.gov.br/cne/arquivos/pdf/PCB11_2000.pdf. Acesso em: 16 set. 2019.

BRASIL. Ministério da Educação. Documento Base Nacional Preparatório a VI

CONFINTEA. Brasília. 2008. Disponível em:

http://pesquisa.in.gov.br/imprensa/jsp/visualiza/index.jsp?data=08/09/2017\&jornal=1\&pagina $=27 \&$ totalArquivos=752. Acesso em: 18 out. 2019 .

BRASIL. Ministério da Educação. Fundo Nacional de Desenvolvimento da Educação.

Resolução/CD/FNDE no 48, de 2 de outubro de 2012. Estabelece orientações, critérios e procedimentos para a transferência automática de recursos financeiros aos estados, municípios e Distrito Federal para manutenção de novas turmas de Educação de Jovens e Adultos, a partir do exercício 2012. Disponível em: https://www.fnde.gov.br/acesso-a-

informacao/institucional/legislacao/item/3849-resolu\%C3\%A7\%C3\%A3o-cd-fnden\%C2\%BA-48,-de-2-de-outubro-de-2012. Acesso em: 16 set. 2019.

BRASIL. Ministério da Educação. Instituto Nacional de Estudos e Pesquisas Educacionais Anísio Teixeira. Indicadores educacionais. 2018. Disponível em:

http://portal.inep.gov.br/web/guest/indicadores-educacionais. Acesso em: 21 jul. 2019.

BRASIL. Ministério da Educação. Lei de Diretrizes e Bases da Educação Nacional. Lei no 9.394, de 20 de dezembro de 1996. Estabelece as diretrizes e bases da educação nacional. Brasília, DF, 1996.

BRASIL. Ministério da Educação. Secretaria da Educação Básica. Base Nacional Comum Curricular. Brasília, DF, 2018. Disponível em: http://basenacionalcomum.mec.gov.br/. Acesso em: 15 nov. 2019. 
CAMPOS, M. B. Educação financeira na matemática do ensino fundamental: uma análise da produção de significados. 2012. 180 f. Dissertação (Mestrado em Educação Matemática) Universidade Federal de Juiz de Fora, Juiz de Fora, 2012.

CAMPOS, M. B.; SILVA, A. M. A produção de significados de estudantes do ensino fundamental para tarefas de educação financeira. Perspectivas da Educação Matemática, Campo Grande, 2014, v. 7, n. 14, p. 283- 298.

CHEROBIM, A. P. M. S.; ESPEJO, M. M. S. B. (org.). Finanças pessoais: conhecer para enriquecer! São Paulo: Atlas, 2010.

COELHO, T. C. F. Educação financeira para crianças e adolescentes. 2014. 69 f.

Trabalho de Conclusão de Curso (Graduação) - Faculdade Estácio de Sá, Juiz de Fora, 2014.

CONEF - Comitê Nacional de Educação Financeira. Educação financeira nas escolas: ensino fundamental. Brasília: CONEF, 2014.

CONTO, S. M. de et al. O comportamento de alunos do ensino médio do vale do Taquari em relação às finanças pessoais. Revista Eletrônica de Estratégia e Negócios, Florianópolis, v. 8, n. 2, 2015. Doi: 10.19177/reen.v8e22015182-206.

D’AQUINO, C. Educação financeira: como educar seu filho. Rio de Janeiro: Campus, 2007.

DA SILVA, I. T.; SELVA, A. C. V. Programa de Educação Financeira nas escolas-ensino médio: uma análise das orientações contidas nos livros do professor e suas relações com a matemática. REnCiMa, São Paulo, v. 9, n. 1, p. 140-157, 2018. Doi:

10.26843/rencima.v9i1.1293.

DREHER, M. T. Empreendedorismo e responsabilidade ambiental: uma abordagem de empreendimentos turísticos. 2004. Tese (Doutorado em Engenharia da Produção) Universidade Federal de Santa Catarina, Florianópolis, 2004.

ENEF - Estratégia Nacional de Educação Financeira . Modelo conceitual e objetivos. 2011. Disponível em: http://www.vidaedinheiro.gov.br/en/modelo-conceitual-e-objetivos/. Acesso em: 10 jun. 2019.

ENEF - Estratégia Nacional de Educação Financeira. Educação Financeira ainda engatinha nas escolas brasileiras. 2018. Disponível em: http://www.vidaedinheiro.gov.br/en/estadaoescolas-brasileiras/. Acesso em: 12 dez. 2019.

ENEF - Estratégia Nacional de Educação Financeira. Governança. 2011. Disponível em: http://www.vidaedinheiro.gov.br/en/enef/. Acesso em: 22 jul. 2019.

ENEF - Estratégia Nacional de Educação Financeira. Plano Diretor e Anexos, 2011b. Disponível em: http://www.vidaedinheiro.gov.br/wp-content/uploads/2017/08/Plano- DiretorENEF-anexos-ATUALIZADO_compressed.pdf. Acesso em: 25 jun. 2019.

FERREIRA, V. A.; RODRIGUES, M. F. Educação de jovens e adultos: modalidade de ensino e direito educacional. Revista Brasileira de Política e Administração da Educação, Brasília, 2016, v. 32, n. 2, p. 571-583. Doi: 10.21573/vol32n22016.63262. 
FONSECA, J. J. S. da. Metodologia da pesquisa científica. Fortaleza: UEC, 2002. (Apostila).

GADOTTI, M.; ROMÃO, J. E. Educação de jovens e adultos: teoria prática e proposta. 8. ed. São Paulo: Cortez, 2006.

HOFMANN, R. M. Educação Financeira no currículo escolar: uma análise comparativa das iniciativas da Inglaterra e da França. 2013. 329 f. Tese (Doutorado) - Universidade Federal do Paraná, Curitiba, 2013.

KUENZER, A. Z. O ensino médio agora é para a vida: entre o pretendido, o dito e o feito. Revista Educação \& Sociedade, São Paulo, Ano XXI, n. 70, abr. 2000. Doi: 10.1590/S010173302000000100003.

LAKATOS, E. M.; MARCONI M. A. Fundamentos de pesquisa metodológica científica. São Paulo: Atlas, 2003.

LUCCI, C. R. et al. Influência da Educação Financeira nas decisões de consumo e investimento dos indivíduos. In: SEMEAD - ADMINISTRAÇÃO NO CONTEXTO INTERNACIONAL, 9., 2006, São Paulo. Anais [...]. São Paulo: 2006. Disponível em: http://sistema.semead.com.br/9semead/resultado_semead/trabalhosPDF/266.pdf. Acesso em: 22 jul. 2019.

MORAES, F.A. Educação financeira: curso de capacitação na formação docente inicial. 2019. Dissertação (Mestrado Profissional em Ensino) - Universidade Estadual do Norte do Paraná, Cornélio Procópio, 2019.

OCDE - Organização de Cooperação e de Desenvolvimento Econômico. Assessoria de Comunicação Social. OECD's Financial Education Project. 2004. Disponível em: www.oecd.org/. Acesso em: 23 out. 2019.

OLIVEIRA, M. K. Jovens e adultos como sujeitos de conhecimento e aprendizagem. Revista brasileira de Educação, n. 12., set.-dez. 1999. Disponível em: http://anped.tempsite.ws/novo_portal/rbe/rbedigital/RBDE12/RBDE12_06_MARTA_KOHL _DE_OLIVEIRA.pdf. Acesso em: 15 nov. 2019.

PARANÁ. Secretaria de Estado da Educação. Diretrizes Curriculares da Educação de Jovens e Adultos. Curitiba: SEED, 2006. Disponível em:

http://www.educadores.diaadia.pr.gov.br/arquivos/File/diretrizes/dce_eja.pdf. Acesso em: 5 mar. 2019.

REBELLO, A. P.; ROCHA FILHO, J. B. Educação Financeira: uma proposta pedagógica para alunos do ensino médio politécnico. Holos, Natal, ano 31, v. 6, 2015. Disponível em: http://www2.ifrn.edu.br/ojs/index.php/HOLOS/article/view/3645/1231. Acesso em: 15 set. 2019. Doi: 10.15628/holos.2015.3645.

RIBEIRO, C. A. S. et al. Educação financeira aplicada à educação de jovens e adultos na região do PADAP, Minas Gerais. Revista Brasileira de Educação e Cultura, São Gotardo, n. 11, p. 92-117, 2015.

RICHARDSON, R. J. Pesquisa social: métodos e técnicas. São Paulo: Atlas, 1999. 
SANTOS, A. B.; SOARES, T. S.; TORRES, N. L. O papel social da educação de jovens e adultos: comunidade escolar do Porto Grande/Nossa Senhora do Socorro-SE. In:

ENCONTRO INTERNACIONAL DE FORMAÇÃO DE PROFESSORES - ENFOPE, 10., 2017. Anais [...]. Aracajú: Universidade Tiradentes, 2017. Disponível em:

file:///C:/Users/anton/Downloads/5195-21199-1-PB.pdf. Acesso em: 23 set. 2019.

SAVOIA, J. R. F.; SAITO, A. T.; SANTANA S. A. Paradigmas da Educação Financeira no Brasil. Revista de Administração Pública, Rio de Janeiro, v. 41, n. 6, p. 1.121 a 1.141, 2007. Doi: 10.1590/S0034-76122007000600006.

SILVA, A. L. P. et al. Finanças pessoais: análise do nível de Educação Financeira de jovens estudantes do Instituto Federal da Paraíba. Principia. João Pessoa, n. 41, p. 215-224, 2018. Doi: 10.18265/1517-03062015v1n41p215-224.

SILVA, A. M.; POWELL, A. B. Um programa de Educação Financeira para a matemática escolar da educação básica. In: ENCONTRO NACIONAL DE EDUCAÇÃO

MATEMÁTICA, 11., Curitiba. Anais [...], Curitiba: Editora PUC-PR, 2013.

SILVA, E. N.; JÚNIOR, S. S. Sistema financeiro e crescimento econômico: uma aplicação de regressão quantílica. Economia Aplicada, Ribeirão Preto, v.10, n. 3, jul.-set. 2006. Doi: 10.1590/S1413-80502006000300007.

ZUCCHETTI, D. T.; MOURA, E. P. G.; MENEZES, M. M. Há espaço para a economia solidária no campo da educação? Revista Diálogo, Canoas, n.18, p. 37-51, jan.-jun. 2011.

Submetido em 14 de fevereiro de 2020.

Aprovado em 10 de junho de 2020. 